\title{
An assessment of pulmonary functions and chest X-ray imaging in smoker and nonsmoker adults
}

\author{
Yogesh Singh ${ }^{1}$, Manish Lamoria ${ }^{2 *}$, Ketaki Poorey ${ }^{3}$, Keerti Mathur ${ }^{4}$, Usha Jaipal ${ }^{5}$ \\ ${ }^{1,3}$ Assistant Professor, ${ }^{2}$ Associate Professor, Department of Physiology, Jaipur National University Institute for Medical Sciences \& Research \\ Centre, Jaipur, INDIA. \\ $\left\{{ }^{4}\right.$ Senior Professor (Retired), Department of Physiology $\}$ \{5Senior Professor, Department of Radiodiagnosis\} S.M.S. Medical College \& \\ Attached Hospitals, Jaipur, Rajasthan, INDIA. \\ Email: mhlamoria@gmail.com
}

$\underline{\text { Abstract }}$

Background: Despite the increasing evidence regarding the hazards of tobacco, its consumption continues to rise. Premature deaths and disabling illnesses, especially related to the pulmonary and cardiovascular system, caused by cigarette smoking, had now reached epidemic proportions and presented the most challenging problem to medical scientists. Tobacco smoke contains a number of substances which may exert an adverse effect on the whole body especially on the respiratory system. Spirometry is the most effective way of determining the severity of damage in lungs. Pulmonary Functions (Spirometry) and Chest X-ray imaging (Conventional and Computer Aided Diagnosis (CAD)) were assessed on smoker $(\mathrm{n}=240)$ and nonsmoker $(\mathrm{n}=240)$ adult population in the Department of Physiology and Radiodiagnosis, S.M.S. Medical College and Attached Hospitals, Jaipur (Rajasthan). Significant $(\mathrm{p}<0.05)$ declines of pulmonary indices such as FVC (L), $\mathrm{FEV}_{1}(\mathrm{~L})$ and $\mathrm{FEV}_{1} / \mathrm{FVC}(\%)$ were observed in smoker as compared with nonsmoker. Significant improved quality and radiological findings (Emphysema, Hyperinflation, Calcification and Other Suspected Abnormalities) were observed in chest X-ray by CAD tool as compared to conventional method. Statistically significant lower values of pulmonary indices found suggesting that functioning of the lung is affected in the group of cigarette smoker than in nonsmoker group. A significant increase in the appearance of radiological findings and quality of chest X-ray in smokers by CAD tool ropes the contribution of image processing in the medical field.

Key Words: Smoking, Chest X-ray, Computer Aided Diagnosis, Pulmonary Function Test

*Address for Correspondence:

Dr Manish Lamoria, Department of Physiology, Jaipur National University Institute for Medical Sciences and Research Centre, Jaipur,

Rajasthan, INDIA.

Email: mhlamoria@gmail.com

Received Date: 11/03/2020 Revised Date: 20/04/2020 Accepted Date: 27/06/2020

DOI: https://doi.org/10.26611/1031511

This work is licensed under a Creative Commons Attribution-NonCommercial 4.0 International License.

(cc) BY-NO

\begin{tabular}{|l|l|}
\hline \multicolumn{2}{|c|}{ Access this article online } \\
\hline Quick Response Code: & Website: \\
\hline & www.medpulse.in \\
& \\
\hline
\end{tabular}

\section{INTRODUCTION}

In today's scenario, the presence of smoke whether industrial, household, or is actively or passively, taken by an individual in the environment is a serious problem. Smoke in any form is hazardous to individuals of every age group. Tobacco smoking is an act in which burnt tobacco is inhaled or smoked. In both developed and developing countries, smoking is one of the main cause of morbidity and mortality. ${ }^{1}$ It is also one of the leading threats to existing and upcoming world health. Smoking affects almost every system in the human body. Smokers have increased risk of lung diseases: Chronic Bronchitis, Emphysema, Chronic Obstructive Pulmonary Disease (COPD) and Carcinoma., ${ }^{2,3}$ Pulmonary function testing is indicated for all persons in whom there are symptoms and a positive response to a suitable respiratory questionnaire. It should be especially indicated for persons with complaint of shortness of breath. In any person, particularly cigarette smokers or asthmatics, spirometry will provide a baseline performance value for comparison with results of future tests. ${ }^{4}$ Spirometry is the most effective way of determining the severity of lung damage. A major advantage of spirometry is that it enables us to detect chronic obstructive pulmonary disease (COPD) 
before symptoms become apparent. It can confirm the presence of COPD even in mild or moderate stage. ${ }^{5}$ Patient having tuberculosis, pneumonia, cancer and chronic obstructive pulmonary disease (COPD), chest radiography is still the first diagnostic step. Assessment of chest X-ray with applications of image processing Computer Aided Diagnosis (CAD) gives meaningful information in a quick way. $\mathrm{CAD}$ techniques bring new means for peering into the human body, helping to reduce the need for more invasive diagnostic and treatment procedures. The aim of the present study was to assess and compare the pulmonary functions as well as radiological findings and quality of Chest X-ray imaging (Conventional and Computer Aided Diagnosis tool) in smoker and nonsmoker adult population.

\section{METHODS}

After taking a prior clearance from Institutional Ethics Committee and informed written consent from the subjects, they underwent medical history assessment and routine clinical examinations before recording of chest Xray and pulmonary functions to exclude any kind of disorder. Height, Weight, Body Mass Index was also recorded using standard instrument and procedures. The assessment of pulmonary function and chest X-ray was carried out in the Department of Physiology and Radiodiagnosis, S.M.S. Medical College and Attached Hospitals, Jaipur (Rajasthan). The subjects were selected randomly from general population, staff members, doctors and patient's attendants of a medical college, who meet up the inclusion criteria. The pulmonary function test, quality comparison and radiological findings of chest X-ray imaging by Conventional method and Computer Aided Diagnosis (CAD) tool assessments were done on smoker $(\mathrm{n}=240)$ and nonsmoker $(\mathrm{n}=240)$ adults:

- Pulmonary Function Test (PFT): Pulmonary Functions were measured as per standard guidelines by using computerized Spirometry. ${ }^{6}$ Testing procedures were explained to each subject prior to test and was conducted in sitting position. For Pulmonary Function Test instruction was giving to each subject to breathe in fully by deep inspiration with their nostrils closed, to seal their lips around the sterile mouthpiece of the spirometer and to forcefully expired air out. The best of three readings was recorded and interpreted. Pulmonary indices such as Forced Vital Capacity (FVC) (L), Forced Expiratory Volume in First Second $\left(\mathrm{FEV}_{1}\right)$ (L) and Forced Expiratory Volume in First Second $\left(\mathrm{FEV}_{1}\right)$ / Forced Vital Capacity (FVC) ratio expressed as percentage $\left(\mathrm{FEV}_{1} /\right.$ FVC \%) was taken in the present study of both groups (smoker and nonsmoker).

Quality comparison and radiological findings of chest Xray (CXR) imaging by conventional method and computer aided diagnosis (CAD) tool was observed in the present study in both groups (smoker and nonsmoker) as follows:

Chest X-ray Imaging:

- Conventional Method: The film based method was routine investigation of chest. In this procedure subject stood in front of the beam, took a deep breath for lungs filled with air and was instructed to hold the breath till image was captured by the radiographer. The Digital Imaging and Communications in Medicine (DICOM) images were stored in the storage drive and captured image printed on film. That output film was read by radiologist on X-ray illumination screen.

- Computer Aided Diagnosis Tool: Matrix Laboratory (Matlab) was developed by MathWorks, which was high performance interactive software and it allows implementation of algorithms, plotting of functions, simulation, matrix computation and data, image and signal processing by the IPT (Image Processing Toolbox). The Digital Imaging and Communications in Medicine (DICOM) images are stored in the storage drive for analysis and further processing. During the storing process of X-ray image, a lot of irrelevant information was added. To remove this irrelevant information and for enhancing the X-ray image, filter processing technique was employed. ${ }^{7}$

Statistical Analysis: Data were entered in excel sheet. Continuous data were summarized in form of mean and standard deviation. Difference in means of pulmonary function parameters of two groups were analyzed using student's unpaired ' $t$ ' test and comparison of radiological findings and quality were analyzed by Chi-square test. The $\mathrm{p}$ value $<0.05$ was considered as statistically significant (S) and $p$ value $>0.05$ is non-significant (NS).

\section{RESULTS}

Table 1: Demographic and Anthropometrical Data of Nonsmoker and Smoker Group

\begin{tabular}{ccccc}
\hline Group $(\mathrm{n}=480)$ & Age (years) & Height $(\mathrm{cm})$ & Weight $(\mathrm{kg})$ & $\mathrm{BMI}\left(\mathrm{Kg} / \mathrm{m}^{2}\right)$ \\
\hline Nonsmoker, $\mathrm{n}=240$ & $39.48 \pm 06.83$ & $167.03 \pm 06.90$ & $60.95 \pm 07.72$ & $21.79 \pm 01.82$ \\
Smoker, $\mathrm{n}=240$ & $39.63 \pm 07.21$ & $167.56 \pm 06.49$ & $61.10 \pm 07.14$ & $21.73 \pm 01.88$ \\
$\mathrm{t}$ value & -0.234 & -0.867 & -0.221 & 0.355 \\
* $\mathrm{p}$ value & $\mathrm{p}=0.815$ & $\mathrm{p}=0.386$ & $\mathrm{p}=0.082$ & $\mathrm{p} \mathrm{0.723}$ \\
$\mathrm{LS}$ & Non Significant & Non Significant & Non Significant & Non Significant \\
\hline
\end{tabular}

Data were presented as Mean + SD; $n=$ number of subjects; $L S=$ Level of Significance at $5 \%$; ${ }^{*} p=$ student's ' $t$ '-test (unpaired) 
Table 2: Selected Respiratory Indices in Nonsmoker and Smoker Group

\begin{tabular}{|c|c|c|c|}
\hline Parameter & $\begin{array}{l}\text { Forced Vital Capacity } \\
\text { FVC (L) }\end{array}$ & $\begin{array}{l}\text { Forced Expiratory Volume in } \\
\text { First Second }\left(\mathrm{FEV}_{1}\right) \text { (L) }\end{array}$ & 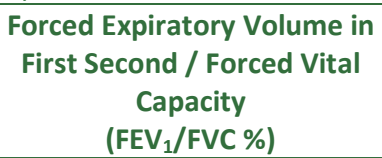 \\
\hline Nonsmoker, $\mathrm{n}=\mathbf{2 4 0}$ & $3.61 \pm 0.66$ & $3.15 \pm 0.56$ & $87.51 \pm 5.97$ \\
\hline Smoker, $\mathrm{n}=\mathbf{2 4 0}$ & $3.06 \pm 0.68$ & $2.52 \pm 0.53$ & $83.26 \pm 10.00$ \\
\hline t value & $8 . \overline{9} 99$ & $12 . \overline{6} 58$ & $5 . \overline{6} 53$ \\
\hline$*_{p}$ value & $p=0.001$ & $p=0.001$ & $p=0.001$ \\
\hline LS & Significant & Significant & Significant \\
\hline
\end{tabular}

Data were presented as Mean + SD; $n$ = number of subjects; LS = Level of Significance at 5\%; * $p=$ student's ' $t$ '-test (unpaired)

Table 3: Radiograph Quality Comparison of Chest X-ray imaging by Conventional Method and Computer Aided Diagnosis (CAD) Tool with regards to Bronchovascular Marking

\begin{tabular}{|c|c|c|c|c|c|c|}
\hline \multirow{2}{*}{\multicolumn{2}{|c|}{ Quality of Chest X-ray }} & Conventional Method & CAD Method & \multirow[t]{2}{*}{ Chi- Square } & \multirow[t]{2}{*}{ *p value } & \multirow[t]{2}{*}{ LS } \\
\hline & & $n,(\%)$ & $n,(\%)$ & & & \\
\hline 1 & High Quality & $346,(72.08)$ & $383,(79.79)$ & \multirow{5}{*}{10.02} & \multirow{5}{*}{$p<0.001$} & \multirow{5}{*}{ 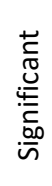 } \\
\hline 2 & Acceptable & $128,(26.67)$ & $096,(20.00)$ & & & \\
\hline 3 & Barely Readable & $006,(01.25)$ & $001,(00.21)$ & & & \\
\hline \multirow[t]{2}{*}{4} & Unreadable & $000,(00.00)$ & $000,(00.00)$ & & & \\
\hline & Total & $480,(100)$ & $480,(100)$ & & & \\
\hline
\end{tabular}

$\mathrm{n}=$ number of subjects, $\%=$ Percentage in parenthesis (\%); $\mathrm{LS}=$ Level of Significance at $5 \%,{ }^{*} \mathrm{p}=$ Chi Square Test

Table 4: Comparisons of Radiological Findings of Chest X-ray Imaging by Conventional Method and Computer Aided Diagnosis (CAD) Tool

\begin{tabular}{|c|c|c|c|c|c|}
\hline \multirow{3}{*}{ S.No. } & \multirow{3}{*}{ Radiological Findings } & Conventional Method & CAD Tool & \multirow{3}{*}{$\begin{array}{c}* \\
\text { p value }\end{array}$} & \multirow{3}{*}{ LS } \\
\hline & & $\begin{array}{c}\begin{array}{c}\text { Smoker Conventional } \\
\mathrm{n}=\mathbf{2 4 0}\end{array}\end{array}$ & $\begin{array}{c}\text { Smoker }_{\text {ComputerAidedDiagnosis }} \\
\mathrm{n}=\mathbf{2 4 0}\end{array}$ & & \\
\hline & & Sc-n,$(\%)$ & $\mathrm{S}_{\mathrm{CAD}-\mathrm{n}_{\mathrm{P}},(\%)}$ & & \\
\hline 1 & Emphysema & $38,(15.83)$ & $47,(19.58)$ & & \\
\hline 2 & Hyperinflation & $16,(06.67)$ & 34, (14.17) & 0 & $\stackrel{\stackrel{u}{ \pm}+}{+}$ \\
\hline 3 & Calcification & $24,(10.00)$ & $24,(11.25)$ & $p<0.03$ & 跔 \\
\hline 4 & Other suspected abnormalities & $08,(03.33)$ & $31,(12.92)$ & & \\
\hline
\end{tabular}

$\mathrm{n}=$ number of subjects, $\%=$ Percentage in parenthesis (\%); Sc- $n_{\mathrm{P}}=$ Radiological findings present in number of subject in Smoker group with Conventional Method; $\mathrm{S}_{C A D} \mathrm{n}_{\mathrm{P}}=$ Radiological findings present in number of subject in Smoker group with CAD Method LS $=$ Level of Significance at $5 \%, * p=$ Chi Square Test

A non-significant difference was found in comparison of demographic variables such as Age (years), Weight $(\mathrm{Kg})$, Height $(\mathrm{cm})$ and Body Mass Index $\left(\mathrm{Kg} / \mathrm{m}^{2}\right)($ Table-1). FVC $(\mathrm{L}), \mathrm{FEV}_{1}(\mathrm{~L})$ and $\mathrm{FEV}_{1} / \mathrm{FVC}$ ratio (\%) were significantly decreased in smoker as compared to nonsmoker group (Table2). Appearance of Bronchovascular Marking in the chest Xray was significantly improved with computer aided diagnosis tool as compared to conventional method (Table-3). On analysis by Chi-square test a significant improved changes ( $p$ $<0.05$ ) were observed in the number of radiological findings present in chest X-rays with CAD tool as compared to conventional method, especially in hyperinflation and other suspected abnormalities (Table-4).

\section{DISCUSSION}

The statistical analysis by unpaired t-test showed a significant decrease $(\mathrm{p}<0.05)$ in pulmonary indices such as FVC $(\mathrm{L})$, $\mathrm{FEV}_{1}(\mathrm{~L})$ and $\mathrm{FEV}_{1} / \mathrm{FVC}$ ratio (\%) in smoker as compared to nonsmoker group. The present study showed lower PFT values in smokers, which may be due to toxic effects of tobacco smoking on respiratory system acting as the major cause of damage to the respiratory system. The above observed difference in pulmonary function of smoker and nonsmoker adult populations illustrates that effects of smoking can lead to tribulations with the normal functioning of respiratory system. The claim of the present study further substantiates the results of earlier research done by Najeeb et al. (2010), ${ }^{8}$ Nawafleh et al. $(2012)^{9}$ and Helal $(2014) .{ }^{10}$ The findings of present study are comparable with the results of Salih et al. $(2015)^{11}$ in terms of considerable decrease in pulmonary functions in smokers relative to the nonsmoker group and they reported that lower pulmonary function signifies greater risk for cardiac, pulmonary disease and lung cancer. The study of Vyas et al. (2014) ${ }^{12}$ compared the lung functions among smoker and non smoker and their findings are contrasting to the result of the present study. The difference in $\mathrm{FEV}_{1} / \mathrm{FVC}$ ratio and $\mathrm{FVC}$ were not significant but partly comparable with a statistically significant difference only in the $\mathrm{FEV}_{1}$ value $(\mathrm{p}<0.05)$ between smoker and nonsmoker groups. A significant $(\mathrm{p}<0.05)$ increased 
number of radiological findings was observed in the chest Xray assessed with CAD tool as compared to chest X-ray with conventional method (Table-4). The finding of the present study was analogous with Mazzone et al. (2013). ${ }^{13}$ Sashidhar et al. (2002) ${ }^{14}$ observed the findings of emphysema in clinically undiagnosed and asymptomatic smokers and reported that chest scans and pulmonary function test may be useful in an early diagnosis of damage in smokers as well as in group of asymptomatic smokers. Eisner et al. $(2011)^{15}$ reported the beneficial role of advance techniques for early detection of disease especially in chest abnormalities and indicated their advantages and disadvantages in reference to the radiation dose. Patient having tuberculosis, pneumonia, cancer and chronic obstructive pulmonary disease (COPD), chest radiography is still the first diagnostic step. Gupta et al. $(2011)^{16}$, Prakash and Khare $(2014)^{17}$ reported that pre and post processing of digital image analysis helps to reduce perceptual and cognitive errors by highlighting abnormalities and characterizing lung patterns. The present study recommended that further evaluation is necessary to determine the role of chest radiography with CAD tool as a screening of lung abnormalities which can minimize the financial burden and hazards of computed tomography (CT) based screening.

\section{CONCLUSION}

Statistically significant decrease values of pulmonary indices in the group of cigarette smoker than in nonsmoker group suggesting lower lung functioning in smokers. A significant increase in the radiological findings and quality of chest $\mathrm{X}$ ray in smokers by computer aided diagnosis (CAD) tool ropes the contribution of image processing in the medical field. A proper approach regarding the implementation and interpretation of basic investigation modality and subsequently the use of advance diagnostic methods allowing the earliest intervention and management, which can improves outcome of the disease. The prediction for the patients with life threatening disease in later phase is correlated with the duration of the disease at the time of diagnosis. CAD techniques may facilitate this prediction as compared to the conventional procedure.

\section{REFERENCES}

1. World Health Organization. Geneva 2008. The global burden of disease: 2004 update (data and statistics).
2. Mitchell RS, Vincent TN, Filley GF. Cigarette Smoking, Chronic Bronchitis, and Emphysema. JAMA. 1964; 188(1):12-16.

3. Young RP, Hopkins RJ, Christmas T, Black PN, Metcalf P, Gamble GD. COPD prevalence is increased in lung cancer, independent of age, sex and smoking history. Eur Respir J. 2009 Aug 1;34(2):380-386.

4. Madan D, Singal P, Kaur H. Spirometric evaluation of pulmonary function tests in bronchial asthma patients. J Ex Sci and Phys. 2012 Dec;6(2):106-111.

5. Barthwal MS, Singh S. Early detection of chronic obstructive pulmonary disease in asymptomatic smokers using spirometry. J Assoc Physicians India. 2014 Mar;62(3):238242.

6. American Thoracic Society/ ERs Task Force: Standardization of lung function testing- Standardization of Spirometry. Eur Respir J. 2005; 26:319-28.

7. Gonzalez RC, 1987. Digital Image Processing. AddisonWesley, Reading, Massaehusetts, 61-201.

8. Najeeb HM. Lung Diffusing Capacity for Carbon Monoxide (DLco-SB): the Influence of cigarette smoking. Iraqi Postgrad Med J. 2010;9(3):328-334.

9. Nawafleh HA, Al-Sayed Abo Zead S, Al-Maghaireh F. Pulmonary Function Test: The value among smokers and nonsmokers. Health Sci J. 2012 Oct 1;6(4):703-713.

10. Helal OF. Impact of smoking on adults lung age and ventilatory function. Int J Physiother Res. 2014;2(2):453-459.

11. Salih SI, Al-hindawi AA. Investigation of the Pulmonary Function Tests in Young Adults Smokers. UK J. Pharm. Biosci. 2015;3(4):39-42.

12. Vyas HP, Vinchhi RP, Sheth MS, Vyas NJ. Comparison of pulmonary function among smokers and non-smokers-A retrospective study. Int J Med Sci and Public Health. 2014 Oct 1;3(10):1232-1234.

13. Mazzone PJ, Obuchowski N, Phillips M, Risius B, Bazerbashi B, Meziane M. Lung cancer screening with computer aided detection chest radiography: design and results of a randomized, controlled trial. PloS one. 2013 Mar 20;8(3):e59650:1-7.

14. Sashidhar K, Gulati M, Gupta D, Monga S, Suri S. Emphysema in heavy smokers with normal chest radiography. Acta radiologica. 2002 Jan 1;43(1):60-65.

15. Eisner MD, Blanc PD, Omachi TA, Yelin EH, Sidney S, Katz $\mathrm{PP}$, Iribarren C. Socioeconomic status, race, and COPD health outcomes. J Epidemiol Community Health. 2011;65(1):2634.

16. Gupta G. Algorithm for image processing using improved median filter and comparison of mean, median and improved median filter. Int.JSoft Comp and Eng. 2011 Nov;1(5):304311.

17. Prakash O, Khare A. Medical image denoising based on soft thresholding using biorthogonal multiscale wavelet transform. Int J Image Grap. 2014;14(01and02):1450002.

\section{Source of Support: None Declared Conflict of Interest: None Declared}

Policy for Articles with Open Access:

Authors who publish with MedPulse International Journal of Physiology (Print ISSN: 2550-7613) (Online ISSN: 2636-4565) agree to the following terms: Authors retain copyright and grant the journal right of first publication with the work simultaneously licensed under a Creative Commons Attribution License that allows others to share the work with an acknowledgement of the work's authorship and initial publication in this journal.

Authors are permitted and encouraged to post links to their work online (e.g., in institutional repositories or on their website) prior to and during the submission process, as it can lead to productive exchanges, as well as earlier and greater citation of published work. 